\title{
Dynein-Dependent Transport of nanos RNA in Drosophila Sensory Neurons Requires Rumpelstiltskin and the Germ Plasm Organizer Oskar
}

\author{
Xin Xu, Jillian L. Brechbiel, and Elizabeth R. Gavis \\ Department of Molecular Biology, Princeton University, Princeton, New Jersey 08544
}

Intracellular mRNA localization is a conserved mechanism for spatially regulating protein production in polarized cells, such as neurons. The mRNA encoding the translational repressor Nanos (Nos) forms ribonucleoprotein (RNP) particles that are dendritically localized in Drosophila larval class IV dendritic arborization (da) neurons. In nos mutants, class IV da neurons exhibit reduced dendritic branching complexity, which is rescued by transgenic expression of wild-type nos mRNA but not by a localization-compromised nos derivative. While localization is essential for nos function in dendrite morphogenesis, the mechanism underlying the transport of nos RNP particles was unknown. We investigated the mechanism of dendritic nos mRNA localization by analyzing requirements for nos RNP particle motility in class IV da neuron dendrites through live imaging of fluorescently labeled nos mRNA. We show that dynein motor machinery components mediate transport of nos mRNA in proximal dendrites. Two factors, the RNA-binding protein Rumpelstiltskin and the germ plasm protein 0skar, which are required for diffusion/entrapment-mediated localization of nos during oogenesis, also function in da neurons for formation and transport of nos RNP particles. Additionally, we show that nos regulates neuronal function, most likely independent of its dendritic localization and function in morphogenesis. Our results reveal adaptability of localization factors for regulation of a target transcript in different cellular contexts.

\section{Introduction}

Intracellular mRNA localization is a conserved mechanism for spatially regulating protein production in polarized cells, such as neurons (Holt and Bullock, 2009; Martin and Ephrussi, 2009). In neurons, mRNA localization targets the expression of specific proteins to dendrites or axons to confer the unique structural and functional properties of these compartments. Requirements for localization of mRNAs to neuronal processes have been demonstrated in dendrite morphogenesis, growth cone navigation, synaptogenesis, and synaptic plasticity (Holt and Bullock, 2009; Doyle and Kiebler, 2011).

We previously identified a role for mRNA localization in dendrite morphogenesis in Drosophila larval class IV dendritic arborization (da) neurons. These sensory neurons elaborate highly branched dendritic trees that innervate the larval epidermis and function in nociception and light avoidance (Hwang et al., 2007; Xiang et al., 2010). Maintenance of these complex dendritic trees requires the translational repression complex formed by Nanos (Nos) and Pumilio (Pum; Ye et al., 2004; Brechbiel and Gavis,

\footnotetext{
Received Dec. 21, 2012; revised Aug. 5, 2013; accepted Aug. 7, 2013.

Author contributions: X.X., J.L.B., and E.R.G. designed research; X.X. and J.L.B. performed research; X.X., J.L.B., and E.R.G. analyzed data; X.X. and E.R.G. wrote the paper.

This work was supported by National Institutes of Health Grant R01 GM067758 to E.R.G. We thank T. Chou, I. Davis, T. Hays, Y. Jan, R. Lehmann, K. Menon, W. Saxton, R. Steward, D. Tracey, M. Welte, K. Zinn, the Drosophila Bloomington stock center, the Vienna Drosophila RNAi Centre, and the Harvard TRiP for fly stocks. We are also grateful to A. Abbaszadeh, B. Bhogal, M. Misra, and C. Tenenbaum for helpful comments on the manuscript.

Correspondence should be addressed to Elizabeth R. Gavis at the above address. E-mail: gavis@princeton.edu. DOI:10.1523/JNEUROSCI.5864-12.2013

Copyright $\odot 2013$ the authors $\quad 0270-6474 / 13 / 3314791-10 \$ 15.00 / 0$
}

2008; Olesnicky et al., 2012) and consequently nos and pum mutants exhibit reduced dendritic branching complexity. nos mRNA forms particles that are dendritically localized and the nos mutant dendritic defect can be rescued by transgenic expression of wildtype nos mRNA but not by a localization-compromised nos derivative, indicating that dendritic localization of nos and local Nos synthesis are essential for dendrite morphogenesis (Brechbiel and Gavis, 2008). Nos and Pum also have non-neuronal functions, including embryonic abdomen formation and germline development. These, too, require spatially regulated Nos synthesis, which is achieved through localization of nos mRNA to the specialized germ plasm at the posterior of the embryo (Becalska and Gavis, 2009; Lasko, 2011).

Targeting and transport of mRNAs to their proper destinations is a highly regulated process. Studies in various cell types have shown that mRNAs are transported as ribonucleoprotein (RNP) particles, most often by motor proteins traveling on microtubules or actin filaments. These particles are assembled through the recognition of cis-acting localization signals by RNAbinding proteins, and the recruitment of additional factors, including translational repressors and motor proteins (Martin and Ephrussi, 2009). Several RNA-binding proteins, including Staufen (Stau) and Fragile X mental retardation protein (FMRP), have been identified in neuronal granules and have been shown to play roles in dendritic mRNA transport in cultured mammalian hippocampal neurons (Tang et al., 2001; Duchaîne et al., 2002; Dictenberg et al., 2008). These granules also contain kinesin motors, which are thought to mediate their transport into the dendrites (Jeong et al., 2007; Dictenberg et al., 2008). FMRP par- 
ticle trafficking has also been observed in Drosophila neurons, in this case requiring components of the dynein motor machinery (Bianco et al., 2010). Less is known about the requirements for transport of specific mRNAs, however.

We have previously shown that localization of nos occurs before fertilization, with nos accumulating in the germ plasm at the posterior of the oocyte through a diffusion and entrapment process independent of microtubules (Forrest and Gavis, 2003). This localization requires the Drosophila heterogeneous nuclear RNP (hnRNP) M homolog Rumpelstiltskin (Rump), which binds directly to nos mRNA, and the germ plasm organizer Oskar (Osk; Wang et al., 1994; Sinsimer et al., 2011). Localized nos RNP particles are subsequently segregated to the germ cell progenitors as they form at the posterior of the embryo, through microtubule-dependent transport (Lerit and Gavis, 2011).

Here we have investigated the mechanism of dendritic nos mRNA localization by analyzing requirements for nos RNP particle motility in class IV da neuron dendrites of intact larvae, through live imaging of fluorescently labeled nos mRNA. We show that dynein motor machinery components mediate transport of nos mRNA in proximal dendrites. In addition to their roles in the diffusion/entrapment-mediated localization of nos in the oocyte, Rump and Osk function in da neurons for the formation and transport of nos RNP particles. Additionally, we show that nos regulates neuronal function, most likely independent of its dendritic localization and function in morphogenesis. Our results reveal adaptability of localization factors for regulation of a target transcript in different cellular contexts.

\section{Materials and Methods}

Fly strains and genetics. The following transgenic strains were used: UASMCP-RFP; nos-(ms2) ${ }_{18}$ (Brechbiel and Gavis, 2008); osk-(ms2) ${ }_{6}$ (Lin et al., 2008); UAS-lacZ-MS2bs (van Gemert et al., 2009), and UAS-RFP.nls (Lipsick and Bilder, personal communication to FlyBase). The following mutant alleles and allelic combination were used: $n o s^{R C} / n o s^{R D}$ (Curtis et al., 1997); pum $^{E T 9} /$ pum $^{E T 7}$ (Lehmann and Nüsslein-Volhard, 1987); $D h c^{6-12} / D h c^{8-1}$ (McGrail et al., 1995; Gepner et al., 1996); BicD ${ }^{18 a} /$ $\mathrm{BicD}^{R 26}$ (Mohler and Wieschaus, 1986); egl $^{\text {wu50 }} / \mathrm{egl}^{3 e}$ (Mach and Lehmann, 1997; Navarro et al., 2004); $K \mathrm{~h}^{17} / K \mathrm{Kc}^{8}$ (Saxton et al., 1991; Brendza et al., 1999); osk ${ }^{54} / o s k^{84}$ and osk ${ }^{54} / o s k^{A 87}$ (Lehmann and Nüsslein-Volhard, 1986, 1991; Vanzo and Ephrussi, 2002); rump ${ }^{1}$ (Jain and Gavis, 2008). Mutant analysis necessitated the use of two different combinations of class IV da neuron GAL4 drivers recombined with UAS$m C D 8$ :GFP transgenes. GAL4 $4^{8-123}$, UAS- $m C D 8$ :GFP on the third chromosome (Ye et al., 2004) was used in combination with mutants on the second chromosome; GAL4 $4^{477}$, UAS-mCD8:GFP on the second chromosome (Grueber et al., 2003) was used in combination with mutants on the third chromosome. UAS-RNAi lines were obtained from the Vienna Drosophila RNAi Center (Dhc: 28054; BicD: 27683; egl: 21779; osk: 107546; rump: 44659) and the Harvard Transgenic RNAi Project collection (pum: JF02267; Khc: HMS01519). The UAS-nosRNAi transgenic lines are described by Menon et al. (2009). UAS-KhcRNAi was expressed using the GAL4 $4^{477}$ driver, and $p p k-m C D 4-G F P$ (Han et al., 2011) was simultaneously used to label the neurons. All other UAS-RNAi lines were expressed using pickpocket1.9-GAL4 (ppk-GAL4; Ainsley et al., 2003) together with UAS-dicer2 (nociception assay) or a recombinant $p p k$ GAL4, UAS-mCD8:GFP chromosome together with UAS-dicer2 (morphology analysis) at $25^{\circ} \mathrm{C}$ (Zhong et al., 2010).

Live imaging and analysis of particle motility. Larvae were anesthetized and mounted for imaging as described in Brechbiel and Gavis (2008) except that a 1:5 chloroform/halocarbon oil 700 mixture was used. Neurons were imaged within 15 min of exposure to anesthesia on a PerkinElmer spinning disc microscope equipped with an EM-CCD camera (Hamamatsu), used with a $60 \times / 1.4$ numerical aperture (NA) oil-immersion objective. Movies were captured at $400 \mathrm{~ms} /$ frame rate in a single focal plane over a range of $30-120 \mathrm{~s}$ as necessary to minimize photobleaching and photo- toxicity. The dorsal-most class IV da neuron, ddaC, from abdominal segments 4-6 was imaged. Particles were tracked semimanually with the Volocity software program (PerkinElmer). Average particle velocities were measured for individual runs of single particles that were visible in at least three consecutive movie frames and the mean average velocity was calculated. Static and motile particle number was quantified from the first 75 frames of each movie and normalized to dendrite length. Statistical significance was determined by the two-tailed Student's $t$ test. Net displacement of a motile particle was measured by determining the vector between its positions at the start and end of the imaging period. The $\chi^{2}$ goodness-of-fit test was applied to test a 1:1 ratio of anterogradeto-retrograde displacement.

Imaging and quantitation of dendrite morphology. Dendrite morphology in late (wandering) third instar larvae was analyzed by direct fluorescence imaging of anesthetized larvae, prepared as described above. Neurons were imaged using a Leica SPE microscope with a $20 \times / 0.7 \mathrm{NA}$ air objective. For quantitation of dendrite termini, neurons were either imaged using a Zeiss LSM510 microscope with a $40 \times / 1.2$ NA waterimmersion objective (neurons visualized using $G A L 4^{8-123}$ and UAS$m C D 8: G F P)$ or a Leica SPE microscope using a $40 \times / 1.25$ NA oilimmersion objective (neurons visualized using GAL4 ${ }^{477}$ and UAS$m C D 8: G F P$ or $p p k-G A L 4$ and UAS-mCD8:GFP). Since the whole dendritic arbor is larger than the $40 \times$ objective field, neurons imaged with $40 \times$ objectives were imaged in overlapping segments to re-create dendritic fields extending from cell body to dorsal midline. Quantitation of $D h c, e g l$, and BicD mutant neurons in Figure 2 was performed using a semi-intact larval preparation, which leads to a lower termini number than that of the anesthesia-based preparation.

Branching complexity was quantified in $z$-series projections of ddaC neurons by counting the total number of terminal branches in a field extending from the cell body to the midline. One neuron from abdominal segment 4,5 , or 6 was analyzed per larva. The two-tailed Student's $t$ test was performed to determine significance between datasets.

Nociception assay. Wandering third instar larvae were rinsed with distilled water and placed on apple juice agar egg collection plate and covered with a thin layer of water to keep the larvae moist. A noxious mechanical stimulus was delivered by firmly pressing on the larval cuticle on the dorsal side in abdominal segments 4,5 , or 6 with an insect pin $(0.1 \mathrm{~mm}$ Minutien pins, Fine Science Tools) held at an angle between a pair of forceps. Each larva was tested once and discarded. A positive score required at least one stereotypic corkscrew rolling response following 1-2 mechanical stimuli. Data were analyzed using the $\chi^{2}$ test.

\section{Results}

nos mRNA particles are transported in da neuron dendrites

Previously, we visualized nos mRNA in class IV da neurons in vivo by fluorescent labeling with the MS2/MS2 coat protein (MCP) tethering system. MS2-tagged nos mRNA labeled with MCP-RFP $\left(n o s^{\star} R F P\right)$ forms motile particles that localize to dendritic branches (Brechbiel and Gavis, 2008). Here we characterize nos particle motility in detail by rapid live-cell imaging under more sensitive microscopy conditions than used previously. Because we had observed that MCP-RFP can form nonspecific particles in da neurons in the absence of MS2-tagged RNA, presumably due to overexpression and self-association (Brechbiel and Gavis, 2008), we also analyzed control neurons expressing only MCP-RFP. Three different combinations of da neuron-specific GAL4 drivers and independent UAS-MCP-RFP transgenic lines were tested, with or without MS2-tagged nos mRNA, expressed under control of its own promoter.

During the brief imaging periods (see Materials and Methods), the majority of particles detected in dendrites of class IV da neurons expressing either MCP-RFP together with MS2-tagged RNA (referred to hereafter as nos ${ }^{\star} R F P$ neurons for simplicity) or MCP-RFP alone (referred to hereafter as MCP-RFP-only neurons) appeared to be stationary or jiggling in place, as previously 

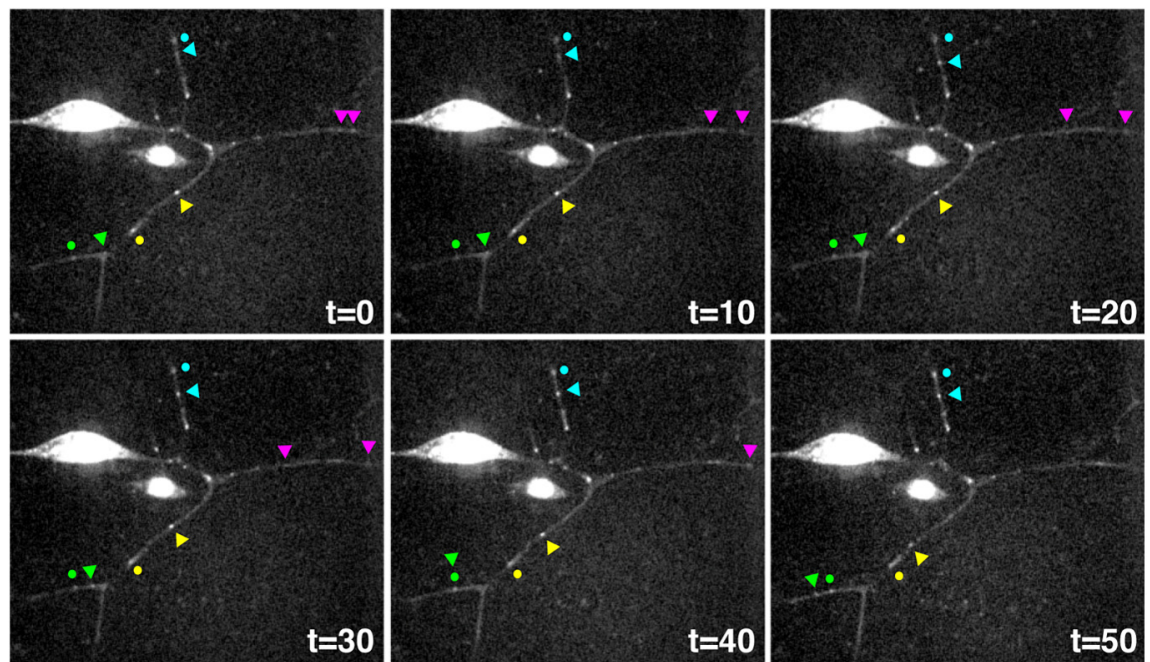

Figure 1. Visualization of RNP particles in da neuron dendrites. Time-lapse image sequence of a ddaC neuron expressing $n s^{*} R F P$. Individual frames are shown at 10 s intervals as noted. Colors are used to highlight examples of motile particles (arrowheads) and static/jiggling particles (dots) within a given branch over the time series. The right-most magenta arrowhead indicates a particle that moves out of the field while the left-most magenta arrowhead indicates a particle that becomes difficult to differentiate from static particles near a branchpoint (see also Movie 1).

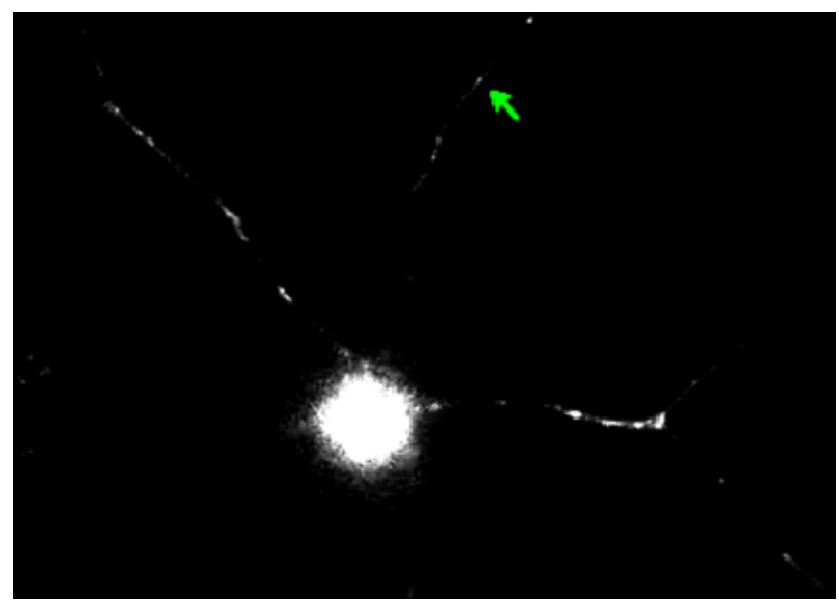

Movie 1. Confocal time-lapse movie of a larval class IV da neuron (ddaC) expressing nos*RFP. Images were captured at 2.3 frames/s and played back at 20 frames/s. Arrows indicate movement of particles.

observed for RNP particles in cultured neurons (Rook et al., 2000; Bianco et al., 2010; Tübing et al., 2010). In addition, we detected particles that exhibited directed movement (defined as motile particles) in both $n o s^{\star} R F P$ and MCP-RFP-only neurons (Fig. 1; Movie 1; data not shown). Unidirectional movement, both retrograde and anterograde, and bidirectional movement, in which particles switched directions, were observed. Similar bidirectional transport of RNP particles has been observed within dendrites from other types of neurons (Doyle and Kiebler, 2011). Motile particles moved through dendritic branch points, from proximal dendrites to distal dendrites and vice versa, but not through branch points from one distal dendrite to another.

Quantification of the total number of dendritic particles normalized to dendrite length shows a trend toward a greater number of particles in dendrites of nos ${ }^{\star} R F P$ neurons versus MCP-RFPonly neurons (Fig. $2 A$ ). Most significantly, the fraction of particles that were motile was consistently higher in $n o s^{\star} R F P$ neurons, with nearly twice as many motile particles as in MCP-RFP-only neurons
(Fig. 2A). In addition, the average velocities of motile particles were significantly greater in $\operatorname{nos}^{\star} R F P$ neurons than in MCP-RFP-only neurons (mean average velocity, 0.55-0.74 $\mu \mathrm{m} / \mathrm{s}$ for $n^{*}{ }^{*} R F P$ neurons vs $0.35-0.50$ $\mu \mathrm{m} / \mathrm{s}$ for MCP-RFP-only neurons; Fig. $2 B$ ). Analysis of the net displacements of motile particles showed a trend toward higher proportions of motile particles undergoing anterograde transport in $n o s^{\star} R F P$ neurons than in MCP-RFP-only neurons (on average 49 vs $37 \%$; Fig. $2 C$ ).

In contrast, when a control MS2tagged lacZ mRNA was expressed in class IV da neurons together with MCP-RFP $\left(\right.$ lac $\left.Z^{\star} R F P\right)$, we observed only a background level of motile particles with average velocities characteristic of MCP-RFPonly particles (Fig. 2D). Moreover, we observed a similar background level of motile particles $(0.02$ particles $/ \mu \mathrm{m})$ moving at an average velocity of $0.30 \mu \mathrm{m} / \mathrm{s}$ when RFP tagged with a nuclear localization signal (UAS-RFP.nls) was expressed in da neurons, consistent with self-aggregation of RFP. Finally, when UAS-nosRNAi was expressed in nos ${ }^{*} R F P$ neurons, both the number and velocities of motile particles were reduced to the levels found in MCP-RFP-only neurons (Fig. 2E).

From these results, we reasoned that there are two populations of particles in the dendrites of $n o s^{\star} R F P$ neurons: nonspecific particles produced by MCP-RFP alone and nos ${ }^{\star} R F P$ particles. These distinct populations of particles, however, can be readily distinguished based on their behaviors, i.e., motility, velocity, and direction of net displacement. Therefore, in all subsequent studies, we compared nos ${ }^{\star} R F P$ neurons with MCP-RFP-only neurons.

\section{Motor requirement for nos mRNA transport}

The linear trajectories and average velocities of $n o s^{\star} R F P$ particles are consistent with motor-dependent movement on cytoskeletal tracks. Previous studies indicated that in contrast to cultured vertebrate neurons, the vast majority of microtubules in the proximal dendrites of Drosophila da neurons are oriented with their minus-ends distal to the cell body (Stone et al., 2008; Zheng et al., 2008). Consistent with this organization, accumulation of endosomes in class IV da neuron dendrites is disrupted by mutations in components of the dynein motor complex (Satoh et al., 2008; Zheng et al., 2008). We therefore tested whether dendritic localization of nos RNP particles is also dynein-dependent.

We investigated a role for dynein in particle transport using either da neuron-specific RNAi, overexpression of the dynactin subunit dynamitin, or a hypomorphic Dynein heavy chain (Dhc) allelic combination that allows survival to larval stages. RNAi knockdown of Dhc using a UAS-DhcRNAi transgene severely compromised da neuron morphogenesis, producing a dramatic dendritic branching defect characteristic of mutations in other dynein motor complex components (Satoh et al., 2008; Zheng et al., 2008; Fig. 3A). Few nos ${ }^{\star} R F P$ or MCP-RFP-only particles were observed in class IV da neuron dendrites upon Dhc RNAi (Fig. $3 B$; data not shown). Similarly, overexpression of dynamitin, which was previously shown to block dynein function (Zheng et al., 2008), also produced a severe branching defect and dramatic loss of dendritic particles (data not shown). In addition, the axons of Dhc RNAi class IV da neurons were thicker than in wild- 
type neurons, as previously observed for mutants for other components of the dynein motor complex (Zheng et al., 2008). Moreover, both MCP-RFP-only and $n s^{\star} R F P$ particles accumulated in the axons of Dhc RNAi neurons (Fig. 3B; data not shown). This aberrant distribution, which resembles the mislocalization of Golgi outposts to class IV da neuron axons in Dynein light intermediate chain mutants (Zheng et al., 2008) and the mislocalization of dendrite-specific vesicle cargos to axons of cultured hippocampal neurons upon dynein inhibition (Kapitein et al., 2010), presumably reflects transport dominated by plus-ended motors such as kinesins in the absence of dynein.

Hypomorphic Dhc mutant da neurons exhibited a milder dendrite morphology defect, indicating partially compromised dynein function (Fig. 3A). While particles in MCP-RFP-only neurons were not affected by reduction of $D h c$ function, the number of motile particles in $n^{*}{ }^{\star} R F P$ neurons and their average velocities were reduced to the background level of MCPRFP-only neurons (Fig. 3C). Moreover, retrograde movement predominated in Dhc mutant neurons (Fig. 3C). Thus, while strong dynein knockdown compromised the behavior of both nos ${ }^{\star} R F P$ and MCP-RFP particles, the analysis of hypomorphic Dhc mutants indicates that $n o s^{\star} R F P$ particles are more sensitive to a reduction in Dhc function. This result is consistent with the observation that localizing RNP particles recruit more dynein motors than nonlocalizing RNP particles (Bullock et al., 2006; Amrute-Nayak and Bullock, 2012).

The Bicaudal-D (BicD) protein interacts with dynein and plays a role in dynein-dependent transport of RNP particles in Drosophila oocytes and early embryos through its interaction with the RNA-binding protein Egalitarian (Egl; Bullock and Ish-Horowicz, 2001). A role for $\mathrm{BicD}$ has recently been identified in class IV da neuron dendrite morphogenesis (Bianco et al., 2010). Therefore, we examined whether Egl also regulates dendrite morphogenesis and whether Egl and $\mathrm{BicD}$ are required for dendritic nos particle movement. Reduction of $e g l$ or BicD function using either mutant alleles or neuron-specific RNAi resulted in a decrease in the number of dendritic termini in class IV da neurons compared with wild-type controls (Fig. 4A). Live imaging of particles in $e g l$ and $B i c D$ RNAi neurons revealed a significant reduction in the number and average velocity of motile particles in $\operatorname{nos}^{\star} R F P$ neurons compared
A
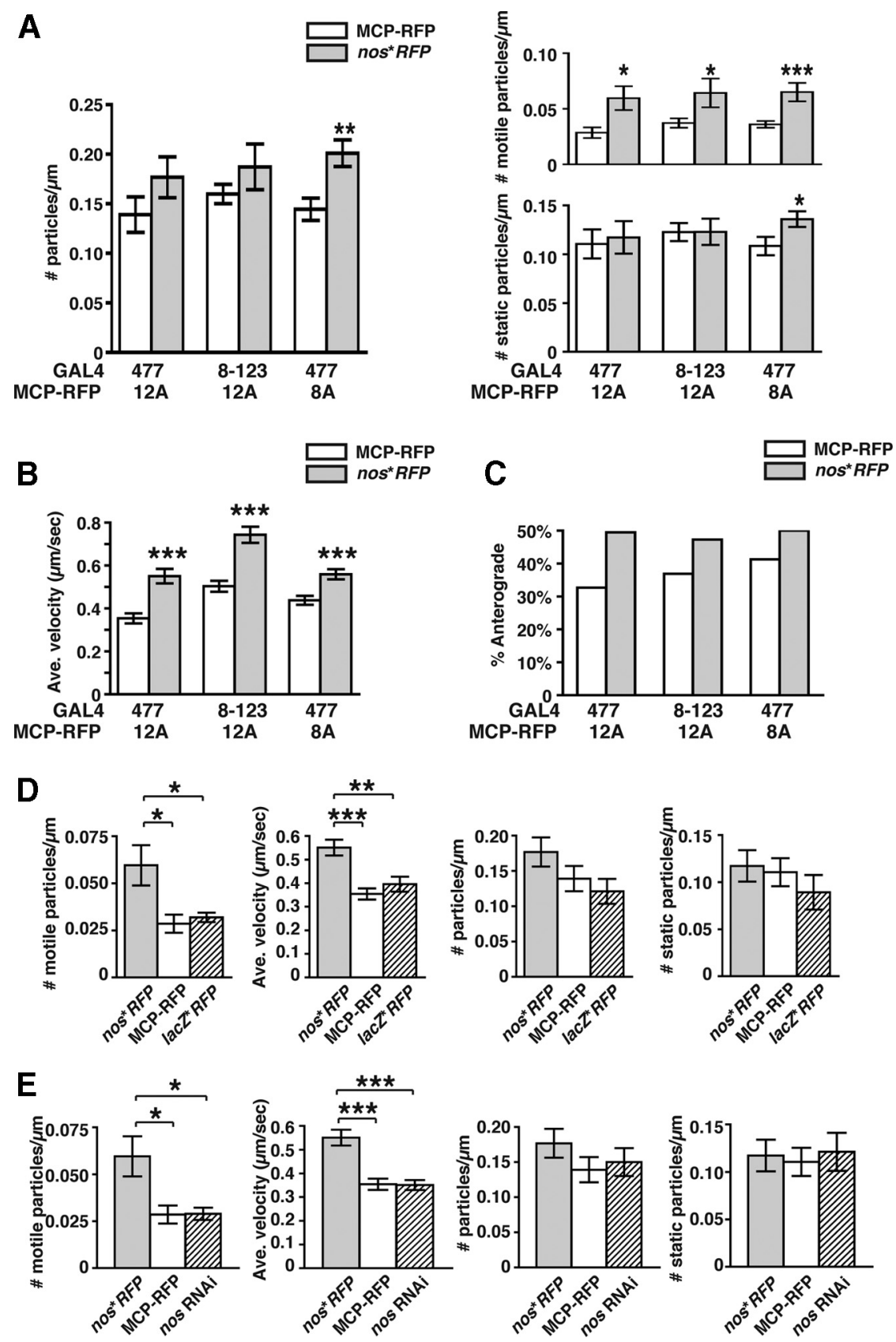

Figure 2. Quantitative analysis of particles in live class IV da neurons. A, Quantification of total particle number and the breakdown of static/jiggling and motile particles observed within the first 30 s of each movie, normalized to the length of the dendrites present within the field. Particles were designated as motile if they moved directionally for at least three consecutive frames. Combinations tested: GAL4 $4^{477}$ with UAS-MCP-RFP ${ }^{12 A}$ (MCP-RFP only, $n=13$ neurons; nos ${ }^{*}$ RFP, $n=13$ neurons); GAL4 $4^{8-123}$ with UAS-MCP-RFP ${ }^{12 A}$ (MCP-RFP only, $n=$ 18 neurons; nos ${ }^{*}$ RFP,$n=13$ neurons); GAL4 ${ }^{477}$ with UAS-MCP-RFP $8 A$ (MCP-RFP only, $n=25$ neurons; $n$ no $^{*} R F P, n=20$ neurons). $\boldsymbol{B}$, Average velocities of motile particles shown in $\boldsymbol{A}$. GAL4 ${ }^{477}$ with UAS-MCP-RFP ${ }^{12 A}$ (MCP-RFP only, $n=54$ particles; $n$ no $^{*}$ RFP, $n=54$ particles); GAL4 $4^{8-123}$ with UAS-MCP-RFP ${ }^{12 A}$ (MCP-RFP only, $n=66$ particles; nos* RFP, $n=55$ particles); GAL4 $4^{477}$ with UAS-MCP-RFP ${ }^{8 A}$ (MCP-RFP only, $n=87$ particles; nos*RFP, $n=87$ particles). C, Percentage of motile particles with net anterograde displacement. In all MCP-RFP-only samples, motile particles exhibited significant bias toward retrograde movement (GAL4 ${ }^{477}$ with UAS-MCP-RFP ${ }^{12 A}, p=0.01$; $G A L 4^{8-123}$ with UAS-MCP-RFP ${ }^{12 A}, p=0.006$; and GAL4 ${ }^{477}$ with UAS-MCP-RFP ${ }^{8 A}, p=0.02$ ), whereas no directional bias was observed for all nos*RFP samples. The three different combinations produced slightly different average values due to different expression levels of the GAL4 drivers and UAS-MCP-RFP transgenes. D, Quantification of the number and average velocity of motile particles, as well as total and static particles in neurons expressing UAS-lacZ-MS2bs with MCP-RFP (lacZ*RFP), compared with nos*RFP and MCP-RFP-only particles. The combination of GAL $4^{477}$ with UAS-MCP-RFP ${ }^{12 A}$ was used in both this and the experiment in $\boldsymbol{E}$. Sample sizes: for particle number, $n=11-13$ neurons were analyzed; for particle velocity, $n=47-54$ particles were analyzed. $E$, Quantification of the number and average velocity of motile particles, as well as total and static particles in neurons expressing UAS-nosRNAiin addition to nos*RFP compared with nos*RFP and MCP-RFP-only neurons. Sample sizes: for particle number, $n=9-13$ neurons; for particle velocity, $n=45-54$ particles. Here and in all subsequent figures, values are the mean \pm SEM; ${ }^{*} p<0.05,{ }^{* *} p<0.01,{ }^{* * *} p<0.001$. 
A

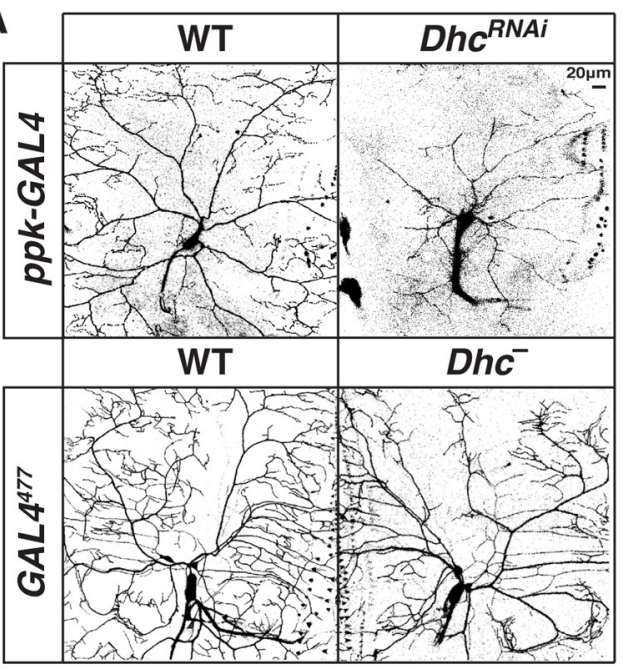

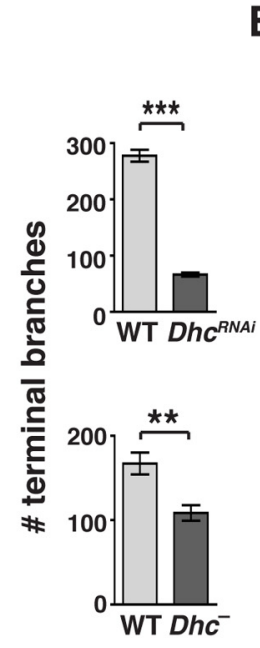

C
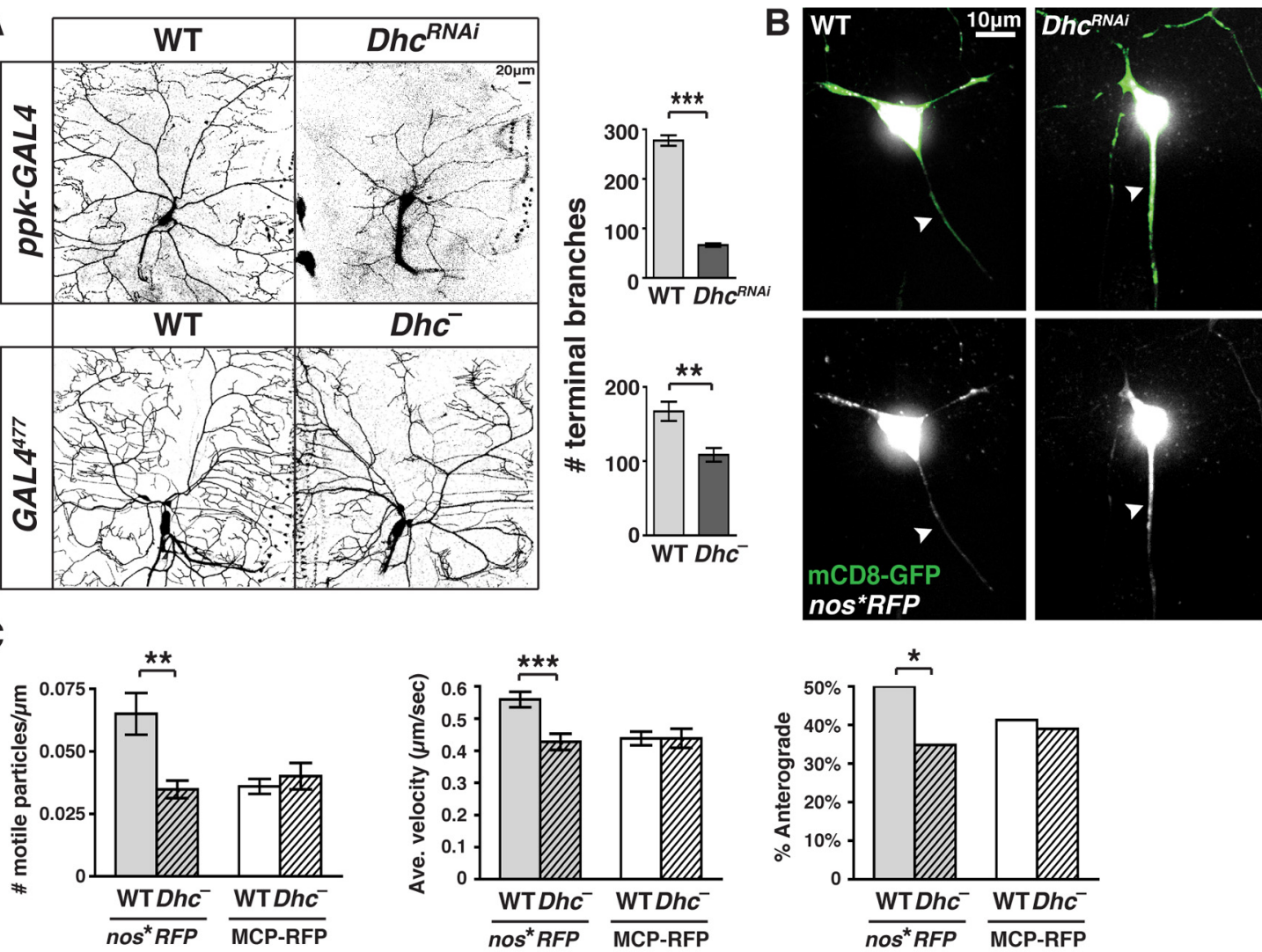

D

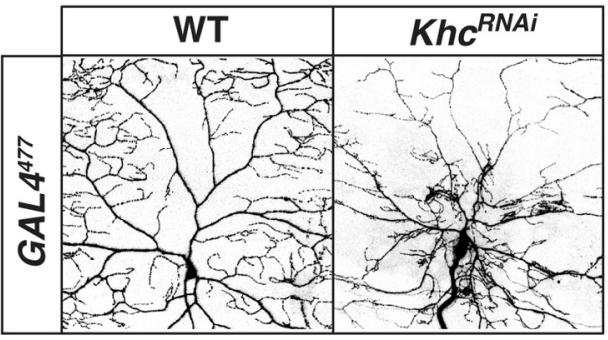

Figure 3. Requirements for molecular motors in nos RNP particle transport. $\boldsymbol{A}$, Confocal z-series projections of ddaC neurons. ppk-GAL4 was used to express UAS-DhcRNAi together with the mCD8-GFP marker and GAL4 ${ }^{477}$ was used to express mCD8-GFP in wild-type (WT) or hypomorphic Dhc mutant (Dhc ${ }^{-}$) neurons. Quantification of the total number of terminal branches is shown at right (RNAi experiment: $n=7-8$ neurons per genotype; mutant experiment: $n=9-10$ neurons per genotype). $\boldsymbol{B}$, Visualization of nos*RFP (white) in live wild-type and Dhc RNAi-expressing ddaC neurons, labeled with mCD8-GFP (green). The combination of GAL4 ${ }^{477}$ with MCP-RFP ${ }^{12 A}$ was used. Arrowheads indicate axons. $C$, Quantification of the number, average velocity, and net displacement of motile particles in hypomorphic Dhc mutant da neurons. The combination of GAL4 ${ }^{477}$ with MCP-RFP ${ }^{8 A}$ was used. Sample sizes: for particle number, $n=12-25$ neurons; for particle velocity and displacement, $n=57-87$ particles. D, Confocal z-series projections of ddaC neurons. For unknown reasons, expression of the UAS- $m$ CD8:GFP transgene by either $p p k$-GAL4 or GAL4 477 is suppressed by KhC RNAi. Therefore, GAL4 ${ }^{477}$ was used to express UAS-KhCRNAi together with ppk-mCD4-GFP.

with wild type, whereas particles in MCP-RFP-only neurons were unaffected (Fig. 4B). We observed a similar specific effect on particle behavior in nos ${ }^{\star} R F P$ neurons in hypomorphic egl and BicD mutants (data not shown). Together, these results indicate that the minus-end-directed transport machinery is required for nos RNP particle transport into dendrites.

The movement of nos ${ }^{\star} R F P$ particles in both anterograde and retrograde directions and their ability to undergo reversals suggests the involvement of the plus-end motor kinesin as well as dynein. Larvae mutant for even hypomorphic Kinesin heavy chain $(K h c)$ allelic combinations are generally unhealthy, exhibiting numerous necrotic spots, flaccidity, and limited mobility. Therefore, we used da neuron-specific RNAi knockdown of Khc to investigate a requirement for kinesin in $n o s^{\star} R F P$ transport. Similarly to Dhc RNAi, Khc RNAi in class IV da neurons produced a strong dendrite morphogenesis defect (Fig. 3D) and re- sulted in few detectable $n o s^{\star} R F P$ or MCP-RFP-only particles (data not shown). A similar effect was observed for Drosophila FMRP particles in cultured brain neurons derived from Drosophila Khc mutant larvae (Bianco et al., 2010). Microtubule organization is not overtly altered in dendrites of class IV da neurons lacking kinesin or dynein motor activity (Satoh et al., 2008; Zheng et al., 2008; data not shown). A previous study showing that transport of Rab-5-containing endosomes into dendrites is compromised in $K h c$ mutant class IV da neurons as well as in neurons mutant for dynein motor components suggested that the requirement for kinesin in anterograde transport could reflect a role for this motor in regulating dynein distribution in the dendrites (Satoh et al., 2008). Thus, the lack of nos ${ }^{\star} R F P$ particles in strong $K h c$ RNAi neurons may result from such an effect on dynein. We cannot, however, rule out a role for kinesin in transport of RNP particles into dendrites. 
A

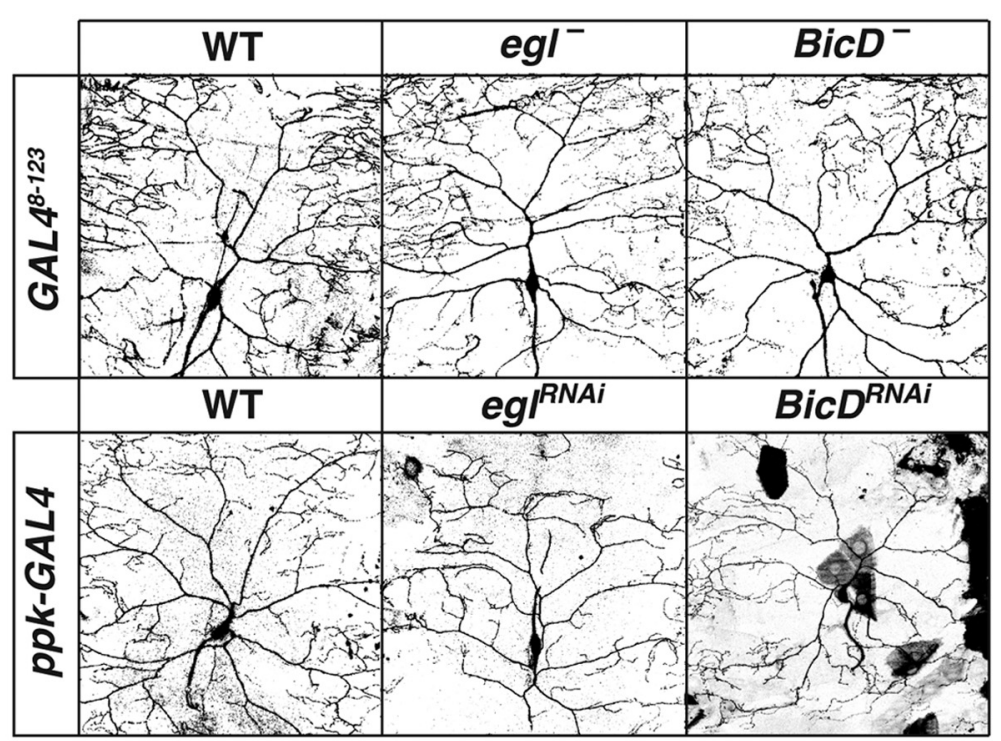

B

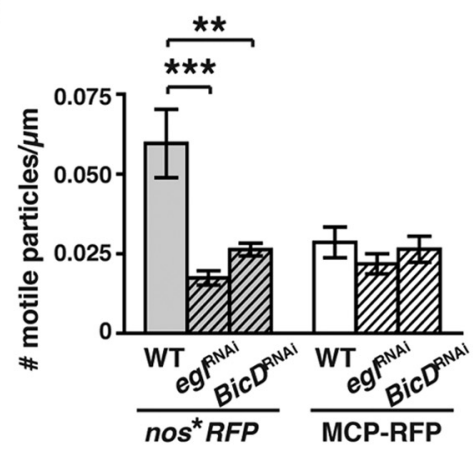

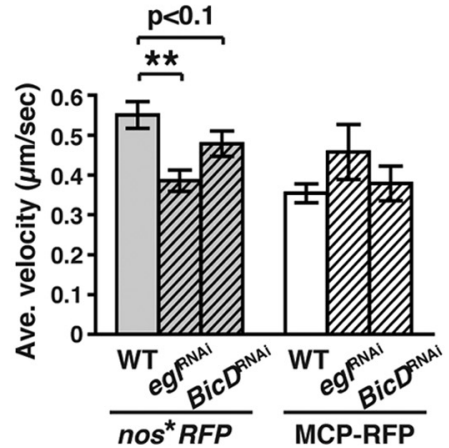

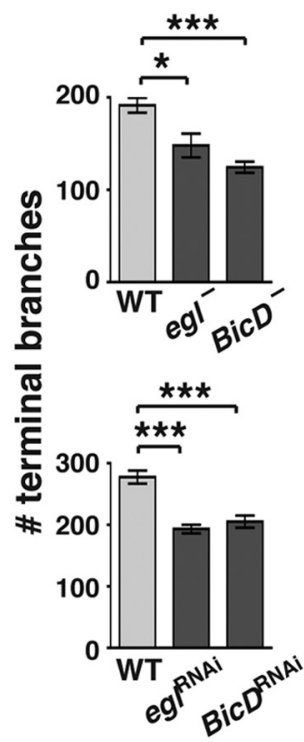

Figure 4. Requirements for motor machinery components in nos RNP particle transport. A, Class IV da neurons in wild-type (WT) and hypomorphic egl and BicD mutant (egl ${ }^{-}$, BicD ${ }^{-}$) larvae visualized by using GAL4 $4^{8-123}$ to express mCD8-GFP or in larvae expressing egl or BiCD RNAi together with mCD8-GFP using ppk-GAL4. Quantification of terminal branch number is shown at right (mutant experiment: $n=10$ neurons per genotype; RNAi experiment: $n=6-8$ neurons per genotype). $\boldsymbol{B}$, Quantification of the number of motile particles ( $n=13-25$ neurons) and average velocity ( $n=36-87$ particles) in wild-type, egl, and BicD RNAi neurons. The combination of GAL4 $4^{477}$ with MCP-RFP ${ }^{12 A}$ was used.

\section{nos mRNA localization pathways share common trans-acting factors}

We have previously shown that dendritic localization of nos and localization of nos to the posterior of the oocyte/embryo are mediated by the same cis-acting localization element in the nos 3 ' untranslated region (Brechbiel and Gavis, 2008). Rump binds to this element and participates in localization of nos to the oocyte posterior via a diffusion and entrapment mechanism (Forrest and Gavis, 2003; Jain and Gavis, 2008; Sinsimer et al., 2011). The entrapment of nos at the posterior, which is thought to occur through the association of nos RNP particles with germ plasm factors assembled at the posterior by the activity of Osk protein, is required to activate nos translation (Becalska and Gavis, 2009). Because dendritic localization and germ plasm localization require the same cis-acting nos localization element, we tested whether Rump and Osk might also play a role in the dendritic localization process. In both rump and osk mutant larvae, class IV da neurons showed loss of dendritic terminal branches that could be completely or partially rescued by supplying one copy of a genomic rump transgene or an MS2-tagged genomic osk transgene, respectively (Fig. $5 A, B$ ). Similar branching defects were produced by neuron-specific rump or osk RNAi (Fig. 5C), resembling those observed in nos mutants or with nos RNAi (Brechbiel and Gavis, 2008; Olesnicky et al., 2012). In addition, both the number of motile particles in nos ${ }^{\star} R F P$ neurons and their average velocities were reduced relative to wild type by mutation or RNAi knockdown of rump or osk (Fig. 5D; data not shown). Moreover, particles in MCPRFP-only neurons were unaffected, indicating that rump and osk are specifically required for formation and/or transport of nos RNP particles (Fig. 5D).

Because localization of osk mRNA during oogenesis is essential for its function in germ plasm assembly, we investigated whether osk might also be localized in da neurons by using the MS2-tagged osk transgene. We observed motile $o s k^{\star} R F P$ particles significantly in excess of MCP-RFP-only particles. These particles moved bidirectionally with average velocities comparable to $n o s^{*} R F P$ particles (Fig. $5 E$; Movie 2). The transport of $o s k^{\star} R F P$ suggests that Osk may function locally in neurons as it does in the oocyte, perhaps through a role in remodeling nos RNP particles once they reach the dendrites.

\section{Transport machinery, but not nos localization, is required} for nociception

Class IV da neurons function as mechanical and thermal nociceptors in Drosophila larvae (Tracey et al., 2003; Hwang et al., 2007; Zhong et al., 2010). We therefore tested whether, in addition to its function in dendritic morphogenesis, nos is required for neuronal function. Following a noxious mechanical stimulus, $\sim 80 \%$ of larvae exhibited the previously described stereotypic nocifensive escape locomotion (NEL) behavior: a corkscrew rolling motion (Fig. 6A). To confirm that this behavior depended on class IV da neuron function, we disabled these neurons selectively by using $p p k$-GAL4, a highly spe- 

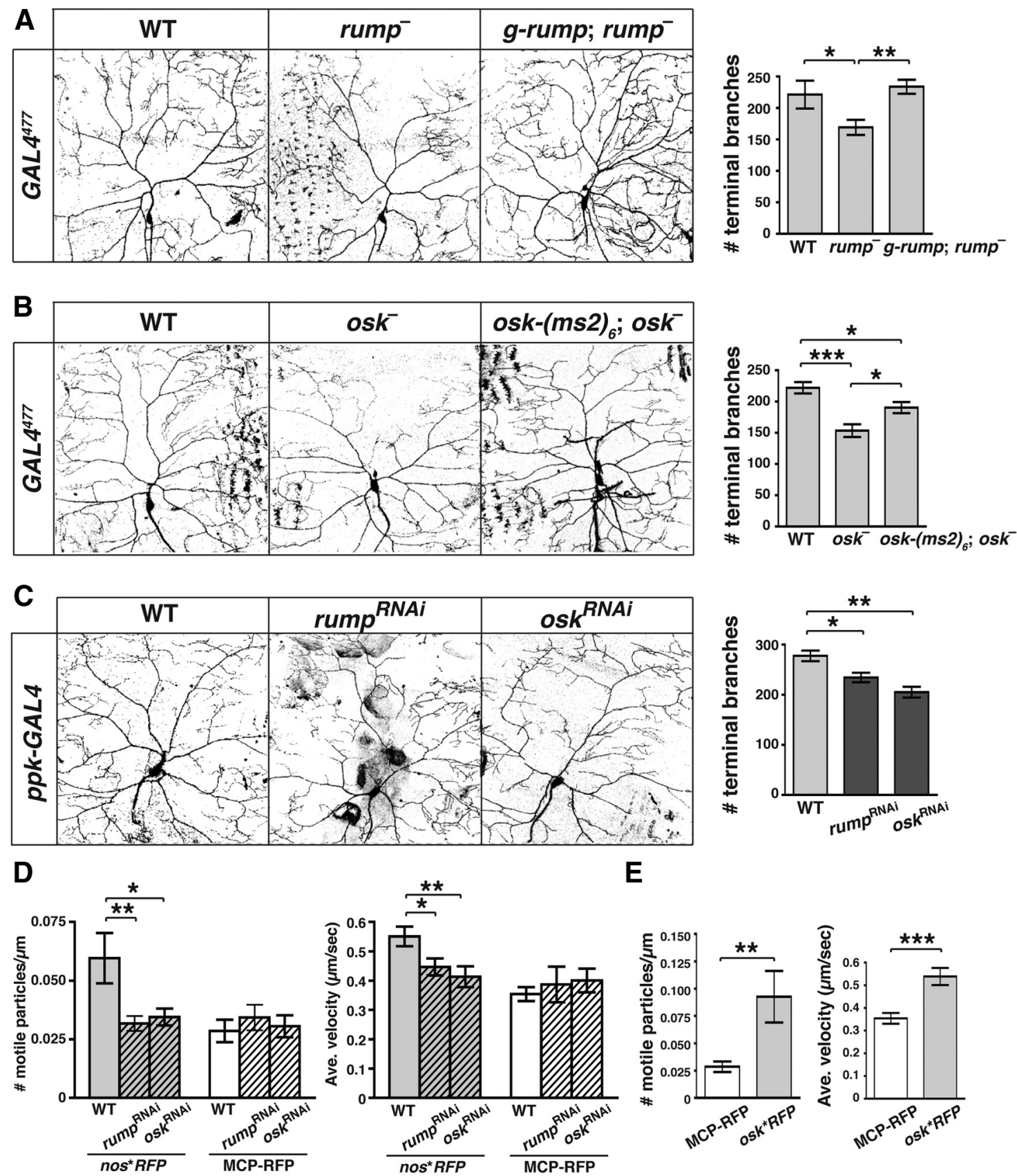

E

Figure 5. Requirement for rump and osk in regulating nos RNA transport. $A$, Confocal $z$-series projections of dda ( neurons. GAL4 ${ }^{477}$ was used to express the mCD8-GFP marker in wild-type (WT), rump mutant (rump ${ }^{-}$), or rump mutant larvae expressing a genomic rump rescue transgene ( $g$-rump; rump ${ }^{-}$). Quantification of terminal branches is shown at right $(n=8-9$ neurons per genotype). $\boldsymbol{B}$, ddaC neurons visualized as in $\boldsymbol{A}$ from wild-type larva, osk mutant larva (osk ${ }^{-}$), or osk mutant larva with MS2-tagged osk transgene [osk-(ms2) ${ }_{6}$; osk ${ }^{-}$]. Quantification of terminal branches is shown at right ( $n=9-10$ neurons per genotype).C, ppk-GAL4 was used to express rump or osk RNAi together with mCD8-GFP. Quantification of terminal branches is shown at right ( $n=$ $6-8$ neurons per genotype). $D$, Quantification of the number ( $n=10-19$ neurons per genotype) and average velocity of motile particles ( $n=21-63$ particles) in rump and osk RNAi neurons. The combination of GAL4 ${ }^{477}$ with MCP-RFP ${ }^{12 A}$ was used in both this and the experiment in E. E, Quantification of the number ( $n=11-13$ neurons) and average velocity ( $n=50-54$ particles) of motile particles in osk*RFP neurons (Movie 2).

cific class IV da neuron driver, to express tetanus toxin light chain (UAS-TnTE). TnTE reduces neurotransmitter release by cleaving the synaptic vesicle protein synaptobrevin, effectively silencing the neuron (Sweeney et al., 1995). Expression of TnTE in class IV da neurons reduced the frequency of NEL behavior to $30 \%$ (Fig. 6A). These results are consistent with results from other comparable nociception studies (Hwang et al., 2007).

When tested in the mechanical nociception assay, nos mutant larvae exhibited a $40 \%$ reduction in NEL behavior relative to control larvae (Fig. 6B). Because execution of NEL behavior involves both sensory and motor neurons and because nos mutants exhibit defects in neuromuscular junction (NMJ) morphogenesis and physiology (Menon et al., 2009), we investigated whether the NEL response requires nos function in da neurons, NMJ, or both. RNAi-mediated knockdown of nos in class IV da neurons resulted in a 30\% reduction in NEL behavior compared with wild-type larvae, similar to that observed for nos mutant larvae (Fig. 6B, C). In contrast, presynaptic NMJ expression of UAS-nosRNAi using OK6-GAL4 or postsynaptic 
NMJ expression using $M h c-G A L 4$, two drivers that have previously been shown to drive UAS-nosRNAi and/or UAS-nos leading to NMJ defects (Menon et al., 2009), had no effect on the NEL response (Fig. $6 C$ ). Together, these data indicate that the NEL response requires nos function specifically in class IV da neurons. Nos, a nonspecific RNAbinding protein, functions in a translational repression complex together with Pum, a sequence-specific RNA-binding protein. Similarly to nos mutant or RNAi larvae, larvae with pum mutations or da neuron-specific pum RNAi also showed a diminished NEL response (Fig. 6B).

We next tested whether motor machinery components and trans-acting factors with roles in nos mRNA localization play a role in nociception, using mutants and class IV da neuron-specific RNAi knockdown. Larvae with reduced $D h c, e g l, B i c D$, and $K h c$ function all exhibited a deficit in NEL behavior (Fig. 6B). However, the effect on NEL behavior did not clearly correlate with the severity of the morphological defect or the effect on nos localization. Thus, defects in trafficking of cargoes distinct from those involved in dendrite morphogenesis per se are likely to be responsible for the NEL deficit in these mutant/RNAi larvae. For example, dynein might be involved in transport of ion channel components important for regulating the physiological functions of the neuron. The specificity of Egl for transport of RNP complexes (Dienstbier et al., 2009) suggests that mRNA transport is, however, important for nociceptive function.

Interestingly, osk mutants exhibited a slightly elevated response relative to wild-type larvae, whereas neuron-specific osk RNAi diminished the response (Fig. 6B). The hypersensitivity of osk mutants was confirmed using multiple allelic combinations (data not shown). We hypothesized that $o s k$ mutations could produce a diver-

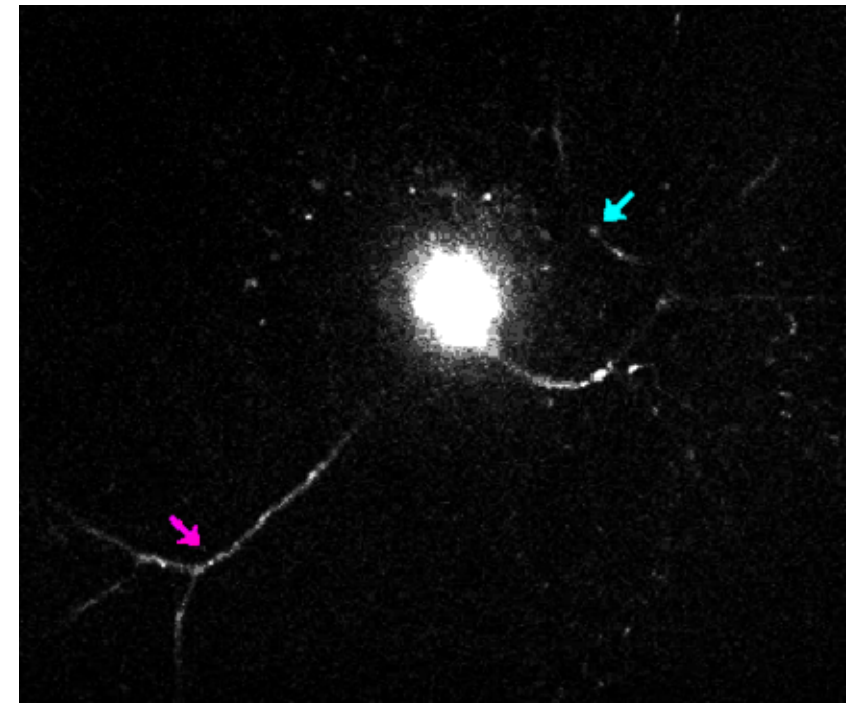

Movie 2. Time-lapse movie of a larval class IV da neuron (ddaC) expressing osk*RFP. Images were captured at 2.3 frames $/ \mathrm{s}$ and played back at 20 frames $/ \mathrm{s}$. Arrows indicate movement of particles.

gent result from osk RNAi if osk functions in multiple cell types to regulate different components of nociception. To test this, we compared the effects of osk RNAi targeted to da neurons by ppk-GAL4 with the effects of ubiquitous osk RNAi using tubP-GAL4. In contrast to da neuron-specific reduction of $o s k$, ubiquitous reduction of $o s k$ by RNAi produced a slight hypersensitive phenotype very similar to
A
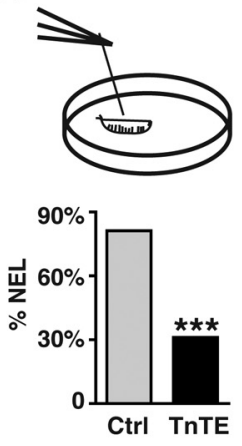

B

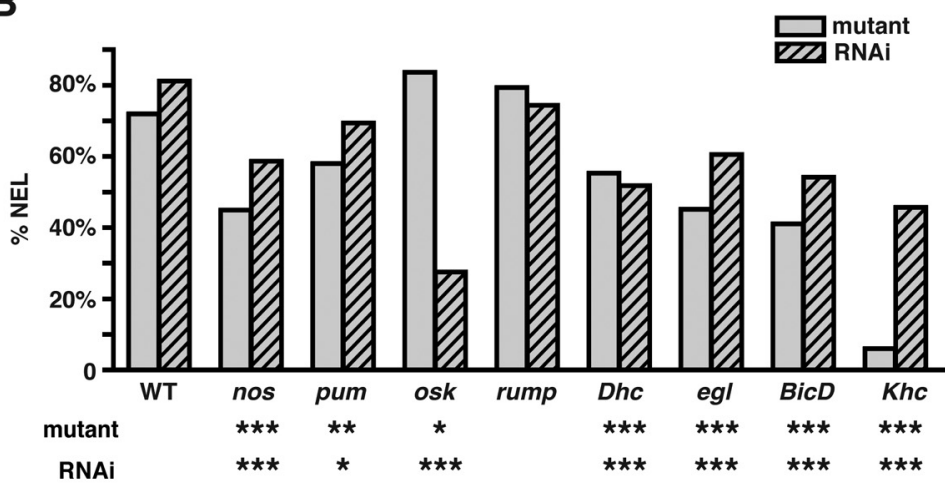

C

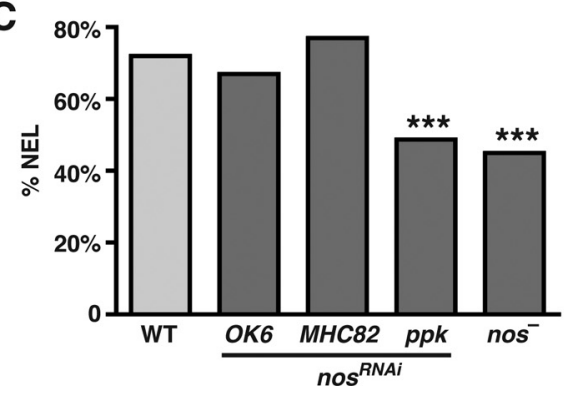

D

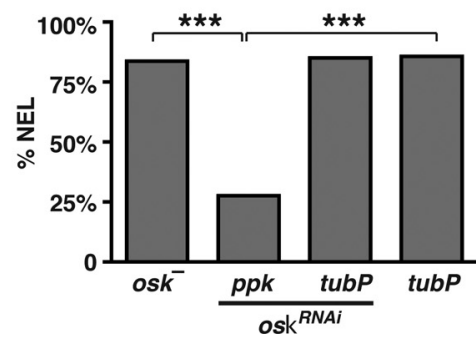

Figure 6. Effects of perturbing RNA localization and transport machinery on nociceptive response. $A$, Nociception assay using an insect pin to apply a mechanical stimulus. The fraction of larvae demonstrating the NEL response upon stimulation was monitored. The NEL response was dramatically decreased in larvae with class IV neurons selectively disabled by ppk-GAL4-mediated expression of TnTE $(n=74)$ relative to ppk-GAL4 control larvae ( $C \mathrm{trl}, n=117)$. B, Nociception assays conducted on larvae with the indicated genes disrupted by mutation or by da neuron-specific RNAi. Mutants: WT $(n=339)$; nos $(n=69)$, pum $(n=143)$, osk $(n=98)$, rump $(n=131)$, Dhc $(n=123)$, egl $(n=62)$, BicD $(n=51)$, Khc $(n=33)$; RNAi: ppk-GAL4; UAS-dicer2 control $(n=$ $117), \operatorname{nos}(n=196)$, pum $(n=124)$, osk $(n=185)$, rump $(n=90)$, Dhc $(n=139)$, egl $(n=155)$, BicD $(n=144)$, Khc ( $n=81)$. C, Nociception assays performed on larvae expressing UAS-nosRNAi in the presynaptic NMJ using OK6-GAL4 ( $n=121)$, the postsynaptic NMJ using MHC82-GAL4 ( $n=126)$, or class IV da neurons using ppk-GAL4 ( $n=117)$ compared with wild-type $(n=339)$ and nos mutant $(n=69)$ larvae. $D$, Nociception assay comparing larvae mutant for osk with larvae expressing UAS-oskRNAi ubiquitously using tubP-GAL4 ( $n=40)$ or specifically in class IV da neurons using ppk-GAL4 ( $n=185)$. tubP-GAL4 alone $(n=49)$ provides a negative control. 
that of osk mutations (Fig. 6D). Thus, while osk is required in class IV da neurons for nociception, it appears to regulate other components of this neural circuit, either in the peripheral nervous system or the CNS.

Surprisingly, despite the requirement for Rump in nos localization, neither mutation of rump nor rump RNAi had an effect on nociception (Fig. 6B). These results suggest that dendritic localization of nos is not required for nos function in nociception. Thus, nos appears to play distinct roles in da neuron morphogenesis and function, with only the former requiring dendritic localization.

\section{Discussion}

We have combined a method that allows live imaging of mRNA in intact Drosophila larvae with genetic analysis to investigate the mechanism underlying transport of nos mRNA in class IV da neurons. Live imaging over the short time periods allowed has provided a snapshot into the steady-state behavior of nos ${ }^{*} R P$ particles in the proximal dendrites of mature da neurons. Our results indicate that anterograde transport of nos RNP particles into and within da neuron dendrites is mediated by dynein and is consistent with the minus-end out model for microtubule polarity in the proximal dendrites of da neurons (Zheng et al., 2008). This model predicts that bidirectional trafficking would be mediated by opposite polarity motors and the predominance of retrograde movement of $n o s^{\star} R F P$ particles when dynein function is partially compromised is consistent with this. Moreover, Rab-5 endosomes, whose accumulation in class IV da neuron dendrites is dynein-dependent, also exhibit bidirectional movement (Satoh et al., 2008), suggesting that different cargos may use similar dendritic transport strategies. Unfortunately, the severe defects caused by loss of kinesin have thus far hampered us and others from confirming a role for kinesin in these events.

The observed bidirectional movement of nos RNP particles resembles the constant bidirectional transport observed for dendritic mRNAs near synapses in hippocampal neurons. In contrast to da neurons, proximal dendrites of mammalian neurons have mixed microtubule polarity (Baas et al., 1988; Stepanova et al., 2003) so that bidirectional trafficking could be mediated by a single motor that switches microtubules or by switching between the activities of plusend and minus-end motors. The association of kinesin with neuronal RNP granule components and inhibition of CaMKII $\alpha$ RNA transport by dominant-negative inhibition of kinesin has implicated kinesin as the primary motor for dendritic mRNA transport (Doyle and Kiebler, 2011). However, a recent study showed that dynein mediates unidirectional transport of vesicle cargoes into dendrites of cultured hippocampal neurons as well as bidirectional transport within the dendrites (Kapitein et al., 2010). Whether dynein plays a role in RNP particle transport in mammalian dendrites as it does in Drosophila neurons remains to be determined.

Despite its prevalence, the role of bidirectional motility is not yet clear. A recently proposed "sushi belt" model suggests that neuronal RNP particles traffic back and forth along the dendrite until they are recruited by an active synapse and disassembled for translation (Doyle and Kiebler, 2011). Although da neuron dendrites do not receive synaptic input, this continual motility may provide a reservoir of nos mRNA that can be rapidly mobilized for translation locally in response to external signals that regulate dendrite branching.

Our studies have shown that nos mRNA can be adapted for different localization mechanisms depending on cellular context: diffusion/entrapment in late oocytes that lack a requisite polarized microtubule cytoskeleton and microtubule-based transport during germ cell formation in the embryo and in class IV da neurons (For- rest and Gavis, 2003; Lerit and Gavis, 2011; this article). Surprisingly, Rump and Osk are specifically required for nos localization in both oocytes and da neurons, suggesting that they function in the assembly or recognition of a fundamental nos RNP that can be adapted to both means of localization. However, because we cannot distinguish individual particles within the cell body, we cannot rule out the possibility that Rump and/or Osk mediate coupling of nos RNP particles to dynein motors rather than particle formation. Within the germ plasm, nos associates with Vasa (Vas), a DEAD-box helicase, and is transported together with Vas into germ cells (Lerit and Gavis, 2011). Although dendritic branching complexity is reduced in vas mutants, we did not detect an effect on dendritic localization of nos RNP particles (data not shown), suggesting that only a subset of germ plasm components are shared by neuronal localization machinery. A role for osk in learning and memory was proposed based on the isolation of an enhancer trap insertion upstream of osk in a screen for mutants with defective long-term memory, but osk function in memory formation has not been directly tested (Dubnau et al., 2003). Notably, however, a recent study showed that the osk ortholog in the cricket Gryllus bimaculatus functions in development of the embryonic nervous system rather than in germ cell formation. Thus, the ancestral function of osk appears to be in neural development, whereas its role in germ plasm formation is a later adaptation in higher insects (Ewen-Campen et al., 2012). Our results showing that Osk protein function is not limited to Dipteran germ plasm organization but also plays an important role in neuronal development and function supports this idea.

Our data indicate that the Nos/Pum complex is not only required for da neuron morphogenesis, but also for nociceptive function. However, nociception does not appear to require local function of Nos/Pum in the dendrites and reduced dendritic branching does not necessarily correlate with a deficit in nociception. These results suggest that morphogenesis and function are regulated separately and that Nos/Pum plays a second role in regulating the somatic translation of proteins required for the nociceptive response. Systematic identification of Nos/Pum targets will be essential to further investigate these different roles.

\section{References}

Ainsley JA, Pettus JM, Bosenko D, Gerstein CE, Zinkevich N, Anderson MG, Adams CM, Welsh MJ, Johnson WA (2003) Enhanced locomotion caused by loss of the Drosophila DEG/ENaC protein Pickpocket1. Curr Biol 13:1557-1563. CrossRef Medline

Amrute-Nayak M, Bullock SL (2012) Single-molecule assays reveal that RNA localization signals regulate dynein-dynactin copy number on individual transcript cargoes. Nat Cell Biol 14:416-423. CrossRef Medline

Baas PW, Deitch JS, Black MM, Banker GA (1988) Polarity orientation of microtubules in hippocampal neurons: uniformity in the axon and nonuniformity in the dendrite. Proc Natl Acad Sci U S A 85:8335-8339. CrossRef Medline

Becalska AN, Gavis ER (2009) Lighting up mRNA localization in Drosophila oogenesis. Development 136:2493-2503. CrossRef Medline

Bianco A, Dienstbier M, Salter HK, Gatto G, Bullock SL (2010) Bicaudal-D regulates fragile $\mathrm{X}$ mental retardation protein levels, motility, and function during neuronal morphogenesis. Curr Biol 20:1487-1492. CrossRef Medline

Brechbiel JL, Gavis ER (2008) Spatial regulation of nanos is required for its function in dendrite morphogenesis. Curr Biol 18:745-750. CrossRef Medline

Brendza KM, Rose DJ, Gilbert SP, Saxton WM (1999) Lethal kinesin mutations reveal amino acids important for ATPase activation and structural coupling. J Biol Chem 274:31506-31514. CrossRef Medline

Bullock SL, Ish-Horowicz D (2001) Conserved signals and machinery for RNA transport in Drosophila oogenesis and embryogenesis. Nature 414: 611-616. CrossRef Medline

Bullock SL, Nicol A, Gross SP, Zicha D (2006) Guidance of bidirectional 
motor complexes by mRNA cargoes through control of dynein number and activity. Curr Biol 16:1447-1452. CrossRef Medline

Curtis D, Treiber DK, Tao F, Zamore PD, Williamson JR, Lehmann R (1997) A CCHC metal-binding domain in Nanos is essential for translational regulation. EMBO J 16:834-843. CrossRef Medline

Dictenberg JB, Swanger SA, Antar LN, Singer RH, Bassell GJ (2008) A direct role for FMRP in activity-dependent dendritic mRNA transport links filopodial-spine morphogenesis to fragile X syndrome. Dev Cell 14:926939. CrossRef Medline

Dienstbier M, Boehl F, Li X, Bullock SL (2009) Egalitarian is a selective RNA-binding protein linking mRNA localization signals to the dynein motor. Genes Dev 23:1546-1558. CrossRef Medline

Doyle M, Kiebler MA (2011) Mechanisms of dendritic mRNA transport and its role in synaptic tagging. EMBO J 30:3540-3552. CrossRef Medline

Dubnau J, Chiang AS, Grady L, Barditch J, Gossweiler S, McNeil J, Smith P, Buldoc F, Scott R, Certa U, Broger C, Tully T (2003) The staufen/pumilio pathway is involved in Drosophila long-term memory. Curr Biol 13:286-296. CrossRef Medline

Duchaîne TF, Hemraj I, Furic L, Deitinghoff A, Kiebler MA, DesGroseillers L (2002) Staufen2 isoforms localize to the somatodendritic domain of neurons and interact with different organelles. J Cell Sci 115:3285-3295. Medline

Ewen-Campen B, Srouji JR, Schwager EE, Extavour CG (2012) oskar predates the evolution of germ plasm in insects. Curr Biol 22:2278-2283. CrossRef Medline

Forrest KM, Gavis ER (2003) Live imaging of endogenous RNA reveals a diffusion and entrapment mechanism for nanos mRNA localization in Drosophila. Curr Biol 13:1159-1168. CrossRef Medline

Gepner J, Li M, Ludmann S, Kortas C, Boylan K, Iyadurai SJ, McGrail M, Hays TS (1996) Cytoplasmic dynein function is essential in Drosophila melanogaster. Genetics 142:865-878. Medline

Grueber WB, Jan LY, Jan YN (2003) Different levels of the homeodomain protein Cut regulate distinct dendrite branching patterns of Drosophila multidendritic neurons. Cell 112:805-818. CrossRef Medline

Han C, Jan LY, Jan YN (2011) Enhancer-driven membrane markers for analysis of nonautonomous mechanisms reveal neuron-glia interactions in Drosophila. Proc Natl Acad Sci U S A 108:9673-9678. CrossRef Medline

Holt CE, Bullock SL (2009) Subcellular mRNA localization in animal cells and why it matters. Science 326:1212-1216. CrossRef Medline

Hwang RY, Zhong L, Xu Y, Johnson T, Zhang F, Deisseroth K, Tracey WD (2007) Nociceptive neurons protect Drosophila larvae from parasitoid wasps. Curr Biol 17:2105-2116. CrossRef Medline

Jain RA, Gavis ER (2008) The Drosophila hnRNP M homolog Rumpelstiltskin regulates nanos mRNA localization. Development 135:973-982. CrossRef Medline

Jeong JH, Nam YJ, Kim SY, Kim EG, Jeong J, Kim HK (2007) The transport of Staufen2-containing ribonucleoprotein complexes involves kinesin motor protein and is modulated by mitogen-activated protein kinase pathway. J Neurochem 102:2073-2084. CrossRef Medline

Kapitein LC, Schlager MA, Kuijpers M, Wulf PS, van Spronsen M, MacKintosh FC, Hoogenraad CC (2010) Mixed microtubules steer dyneindriven cargo transport into dendrites. Curr Biol 20:290-299. CrossRef Medline

Lasko P (2011) Posttranscriptional regulation in Drosophila oocytes and early embryos. Wiley Interdiscip Rev RNA 2:408-416. CrossRef Medline

Lehmann R, Nüsslein-Volhard C (1986) Abdominal segmentation, pole cell formation, and embryonic polarity require the localized activity of oskar, a maternal gene in Drosophila. Cell 47:141-152. CrossRef Medline

Lehmann R, Nüsslein-Volhard C (1987) Involvement of the pumilio gene in the transport of an abdominal signal in the Drosophila embryo. Nature 329:167-170. CrossRef

Lehmann R, Nüsslein-Volhard C (1991) The maternal gene nanos has a central role in posterior pattern formation of the Drosophila embryo. Development 112:679-691. Medline

Lerit DA, Gavis ER (2011) Transport of germ plasm on astral microtubules directs germ cell development in Drosophila. Curr Biol 21:439448. CrossRef Medline

Lin MD, Jiao X, Grima D, Newbury SF, Kiledjian M, Chou TB (2008) Drosophila processing bodies in oogenesis. Dev Biol 322:276-288. CrossRef Medline

Mach JM, Lehmann R (1997) An Egalitarian-BicaudalD complex is essen- tial for oocyte specification and axis determination in Drosophila. Genes Dev 11:423-435. CrossRef Medline

Martin KC, Ephrussi A (2009) mRNA localization: gene expression in the spatial dimension. Cell 136:719-730. CrossRef Medline

McGrail M, Gepner J, Silvanovich A, Ludmann S, Serr M, Hays TS (1995) Regulation of cytoplasmic dynein function in vivo by the Drosophila Glued complex. J Cell Biol 131:411-425. CrossRef Medline

Menon KP, Andrews S, Murthy M, Gavis ER, Zinn K (2009) The translational repressors Nanos and Pumilio have divergent effects on presynaptic terminal growth and postsynaptic glutamate receptor subunit composition. J Neurosci 29:5558-5572. CrossRef Medline

Mohler J, Wieschaus EF (1986) Dominant maternal-effect mutations of Drosophila melanogaster causing the production of double-abdomen embryos. Genetics 112:803-822. Medline

Navarro C, Puthalakath H, Adams JM, Strasser A, Lehmann R (2004) Egalitarian binds dynein light chain to establish oocyte polarity and maintain oocyte fate. Nat Cell Biol 6:427-435. CrossRef Medline

Olesnicky EC, Bhogal B, Gavis ER (2012) Combinatorial use of translational co-factors for cell type-specific regulation during neuronal morphogenesis in Drosophila. Dev Biol 365:208-218. CrossRef Medline

Rook MS, Lu M, Kosik KS (2000) CaMKII $\alpha$ 3' untranslated region-directed mRNA translocation in living neurons: visualization by GFP linkage. J Neurosci 20:6385-6393. Medline

Satoh D, Sato D, Tsuyama T, Saito M, Ohkura H, Rolls MM, Ishikawa F, Uemura T (2008) Spatial control of branching within dendritic arbors by dynein-dependent transport of Rab5-endosomes. Nat Cell Biol 10: 1164-1171. CrossRef Medline

Saxton WM, Hicks J, Goldstein LS, Raff EC (1991) Kinesin heavy chain is essential for viability and neuromuscular functions in Drosophila, but mutants show no defects in mitosis. Cell 64:1093-1102. CrossRef Medline

Sinsimer KS, Jain RA, Chatterjee S, Gavis ER (2011) A late phase of germ plasm accumulation during Drosophila oogenesis requires Lost and Rumpelstiltskin. Development 138:3431-3440. CrossRef Medline

Stepanova T, Slemmer J, Hoogenraad CC, Lansbergen G, Dortland B, De Zeeuw CI, Grosveld F, van Cappellen G, Akhmanova A, Galjart N (2003) Visualization of microtubule growth in cultured neurons via the use of EB3-GFP (end-binding protein 3-green fluorescent protein). J Neurosci 23:2655-2664. Medline

Stone MC, Roegiers F, Rolls MM (2008) Microtubules have opposite orientation in axons and dendrites of Drosophila neurons. Mol Biol Cell 19: 4122-4129. CrossRef Medline

Sweeney ST, Broadie K, Keane J, Niemann H, O’Kane CJ (1995) Targeted expression of tetanus toxin light chain in Drosophila specifically eliminates synaptic transmission and causes behavioral defects. Neuron 14: 341-351. CrossRef Medline

Tang SJ, Meulemans D, Vazquez L, Colaco N, Schuman E (2001) A role for a rat homolog of Staufen in the transport of RNA to neuronal dendrites. Neuron 32:463-475. CrossRef Medline

Tracey WD Jr, Wilson RI, Laurent G, Benzer S (2003) painless, a Drosophila gene essential for nociception. Cell 113:261-273. CrossRef Medline

Tübing F, Vendra G, Mikl M, Macchi P, Thomas S, Kiebler MA (2010) Dendritically localized transcripts are sorted into distinct ribonucleoprotein particles that display fast directional motility along dendrites of hippocampal neurons. J Neurosci 30:4160-4170. CrossRef Medline

van Gemert AM, van der Laan AM, Pilgram GS, Fradkin LG, Noordermeer JN, Tanke HJ, Jost CR (2009) In vivo monitoring of mRNA movement in Drosophila body wall muscle cells reveals the presence of myofiber domains. PLoS ONE 4:e6663. CrossRef Medline

Vanzo NF, Ephrussi A (2002) Oskar anchoring restricts pole plasm formation to the posterior of the Drosophila oocyte. Development 129:3705-3714. Medline

Wang C, Dickinson LK, Lehmann R (1994) Genetics of nanos localization in Drosophila. Dev Dyn 199:103-115. CrossRef Medline

Xiang Y, Yuan Q, Vogt N, Looger LL, Jan LY, Jan YN (2010) Lightavoidance-mediating photoreceptors tile the Drosophila larval body wall. Nature 468:921-926. CrossRef Medline

Ye B, Petritsch C, Clark IE, Gavis ER, Jan LY, Jan YN (2004) Nanos and Pumilio are essential for dendrite morphogenesis in Drosophila peripheral neurons. Curr Biol 14:314-321. CrossRef Medline

Zheng Y, Wildonger J, Ye B, Zhang Y, Kita A, Younger SH, Zimmerman S, Jan LY, Jan YN (2008) Dynein is required for polarized dendritic transport and 
uniform microtubule orientation in axons. Nat Cell Biol 10:1172-1180. CrossRef Medline

Zhong L, Hwang RY, Tracey WD (2010) Pickpocket is a DEG/ENaC protein required for mechanical nociception in Drosophila larvae. Curr Biol 20: 429-434. CrossRef Medline 